\title{
Stage II Keratoconjunctivitis in a Goat: A Case report
}

\author{
*Faez Firdaus Jesse Abdullah ${ }^{1,3}$, Nurul Syazwani Radzuan ${ }^{1}$, Abdulnasir \\ Tijjani $^{2,5}$, Lawan Adamu ${ }^{1,5}$, Yusuf Abba, ${ }^{2,5}$, Konto Mohammed ${ }^{1,5}$, Abdinasir \\ Yusuf Osman ${ }^{1,2}$, Noorashimah Roslim ${ }^{4}$, Dayang Norhaizam Awang ${ }^{4}$, Abdul \\ Aziz Saharee ${ }^{1}$, Mohammed Zamri Saad ${ }^{2}$, Abdul Wahid Haron ${ }^{1,2}$ \\ ${ }^{I}$ Department of Veterinary Clinical Studies; ${ }^{2}$ Department of Veterinary Pathology and Microbiology; ${ }^{3}$ Research \\ Centre for Ruminant Disease, ${ }^{4}$ University Veterinary Hospital, Faculty of Veterinary Medicine, Universiti Putra \\ Malaysia, 43400 UPM Serdang, Selangor, Malaysia; ${ }^{5}$ Faculty of Veterinary Medicine, University of Maiduguri, \\ PMB 1069, Borno State, Nigeria.
}

Abstract: A two year old Australian Feral male goat weighing $30 \mathrm{~kg}$ was presented to the large animal unit of Universiti Putra Malaysia Veterinary Hospital with the clinical signs of conjunctivitis and corneal ulceration with purulent ocular discharge. A sterile swab was taken from the eyefor bacteriological culture and the culture yielded a mixed growth of Pseudomonas aeroginosa and Moraxella caprae.The conditionwas diagnosed as pink eye disease. The goat was administered $3 \mathrm{ml}$ of $20 \mathrm{mg} / \mathrm{kgoxytetracyclinesubconjunctival} \mathrm{injection} \mathrm{of} 0.4 \mathrm{ml}$, intravenous injection of $2.2 \mathrm{mg} / \mathrm{kg}$ Flunixin meglumine (antipyretic) agent, topical application of terramycine eye ointment and infusion of $2 L$ of $0.6 \% \mathrm{Nacl}$ solution. The signs of conjunctivitis and corneal ulcersof the eye had substantially reduced five days post treatment. Quarantine of infected animals, good quality feeding and fly control wasrecommendedas preventive measures.

Keywords: Pink eye, goat, Moraxella caprae, bacteriology

\section{Introduction}

Infectious Keratoconjunctivitis or commonly known as pink eye is a contagious bacterial disease of the eye. This infection will cause the inflammation of the tissue lining the eyelid, the cornea and conjunctiva ultimately causing ulceration which may progress to produce pain and worsen leading to temporary or permanent blindness (Jesse et al., 2013). In sheep and goats, Keratoconjunctivitis may be associated with Mycoplasma conjunctivae and Chlamydophila pecorum. However, other aerobic bacteria can also lead to this condition, and these includePseudomonas species and Staphylococcus aureus (Giacometti et al., 2002). In cattle and sheep, Listeria monocytogenes has also been incriminated with keratitis resulting from direct inoculation of contaminated silage into the eye (Evans et al., 2004). Important causative agent of pink eye in cattle is Moraxella bovis whichis rarely involved in caprine Keratoconjunctivitis. A very closely related species, Moraxella caprae has been isolated from normal goats (Kodjo et al. 1995). According to Browning(2007), animals with conjunctivitis showed clinical signs such as eye discharge, red and swollen eyes, and formation of new blood vessels, cloudiness and ulceration. Pinkeye is of major economic significance to livestock producers through decreased weight gain, decreased milk production, and treatment costs (Whittier et al., 2009).

\section{Case History}

Two years old Australian Feral male goat weighing 30kg had reddish and opaque left eye was presented to Universiti Putra Malaysia Veterinary Hospital. The goat was managed intensively.

Upon physical examination, the goat was dehydrated; dull and depressed with rough hair coat and body condition score of $2 / 5$ (Figure 1). The rectal temperature was high $40.9{ }^{\circ} \mathrm{C}$ indicative of pyrexia. Other vital parameters were within thenormal range. Examination of the left eye revealed conjunctivitis, corneal ulceration and purulent discharges (Figure 2), while the right eye was normal (Figure 3). 


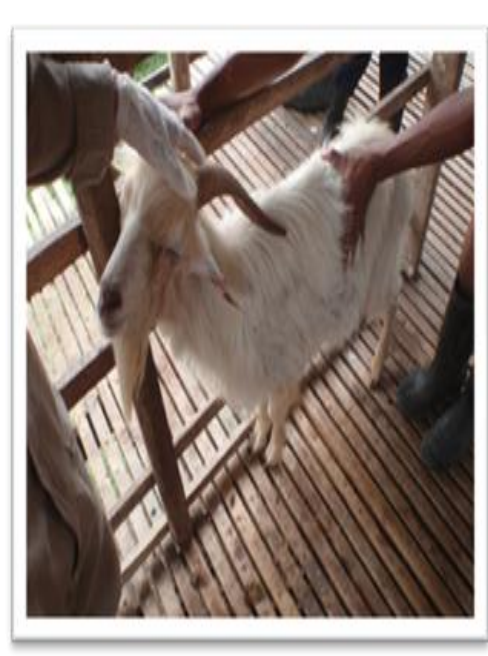

Fig. 1: Shows goat with rough hair coat.

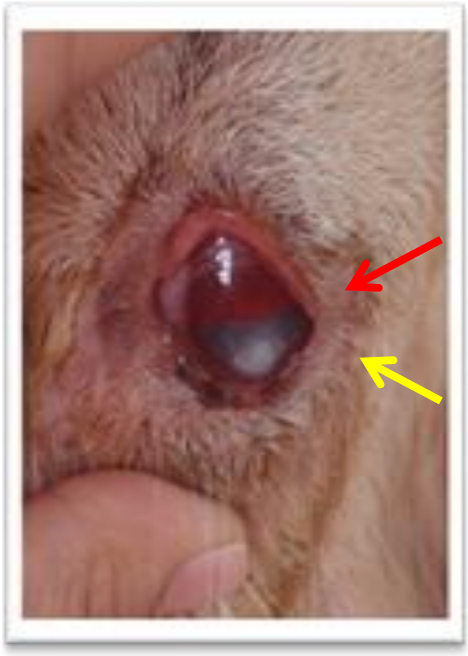

Fig. 2: Shows reddening of the conjunctiva (red arrow) and a corneal ulcer(yellow arrow) in the left eye.

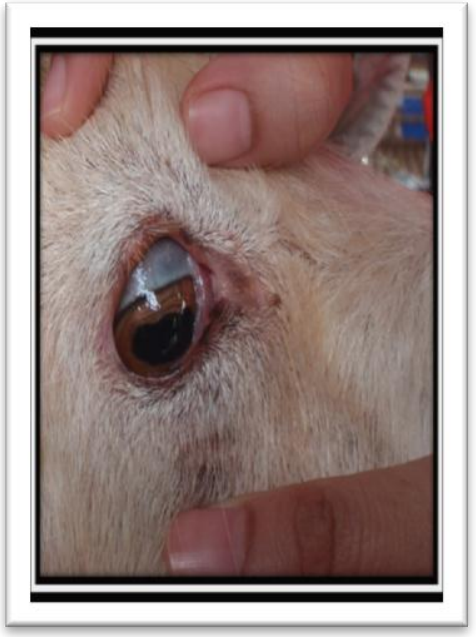

Fig.3: Shows a normal right

eye.

\section{Laboratory investigation}

Asterile eye swab sample of the left eye was taken and sent to the Microbiology Laboratory, Faculty of Veterinary Medicine, Universiti Putra Malaysia for culture, isolation and identification. The laboratory investigation results revealed a mixed growth of Pseudomonas aeroginosa and Moraxella caprae.

\section{Diagnosis}

Based on theclinical signs of pyrexia, conjunctivitis, corneal ulcer, purulent ocular discharges and microbiology results, the case was diagnosed as pink eye (conjunctivitis).

\section{Treatment}

The goat was administered $3 \mathrm{ml}$ Oxytetracyline $(20 \mathrm{mg} / \mathrm{kg})$ intramuscularly once, followed by a single dose of sub-conjunctival injection of $0.4 \mathrm{ml}$ oxytetracycline $(20 \mathrm{mg} / \mathrm{kg})$ at the ventral conjunctival fornix to provide high localized antibiotic concentration at affected area. Terramycin eye ointment was prescribed to be applied topically three times daily (TID) for seven days. Flunixin meglumine was also given intravenously at the dosage of $(2.2 \mathrm{mg} / \mathrm{kg})$ twice daily (BID) for three days, while a rehydration infusion of $2 \mathrm{~L}$ of $0.9 \%$ Sodium Chloride was given intravenously.

\section{Prognosis}

Thesigns of conjunctivitis and corneal ulcer of the left eye has subsided on the fifth day of post treatment.Thus, the prognosis was good since the goat had showed positive response to the treatments given.

\section{Discussion}

Pink eye disease has been reported to progressthrough four stages according to severity. At stage 4, there iscomplete ulceration of the cornea, protrusion and sticking of the iris to the cornea with partial or complete blindness (Whittier et al., 2009). The present case was diagnosed at the second stage of the disease since the ulcer (white spot) did not fully cover the cornea (figure 2). Stress has been reported as one of the predisposing factors to pink eye disease (Browning, 2007). In the present case report, the goat was said to have been transported from Australia and developed the condition two weeks on arrival into the farm. Transportation being one of the causes of stress could have precipitated the condition in the goat. Other predisposing factors include bright sunlight (Rathert, 2008) and dusty environment (Mathews, 2009). Poor hygiene condition in farmshave been reported to be another predisposing factor to the disease, as this will attract flies which are mechanical vectors for the transmission of the causative agent (Drovers, 2011).

Both systemic and topical antibiotic treatments have been administered in the present case. Long acting oxytetracycline $(20 \mathrm{mg} / \mathrm{kg}$ ) was administered intramuscularly as recommended (Whittier, 2009). Topical treatment has been reported to speed up the recovery process of the affected animal (Pugh and Baird, 2012). Terramycin eye ointment was prescribed to be applied topically three times daily. Subconjunctival injection has been reported to be effective if it remains localized (Matthews, 2009). In the present case $0.4 \mathrm{ml}$ of 
oxytetracycline was injected at the subconjunctival region to provide high local concentration of the drug in the affected area.Early treatment of pinkeye is important, not only for a successful outcome of the individual animal affected, but also to stop the shedding of the bacteria in order to decrease the risk of transmission to other animals (Whittier, 2009). The prognosis in the present case was good since it was discovered early and treatment was promptly instituted.

\section{Conclusion and recommendations}

The chances for recovery are high if cases of pink eye are reported in time and immediate treatment instituted as reported in the present case. Quarantine of newly purchased animals, adequate quality feeding and fly control is recommended. In the present case the owner was advised to isolate the goat from the rest of the flock until full recovery is achieved.

\section{Acknowledgement}

The authors wish to acknowledge En Nazim Razali Kanini, En Mohd Jefri and Mr. Velloo of University Veterinary Hospital (UVH), and Faculty of Veterinary Medicine Universiti Putra Malaysia for their technical assistance.

\section{References}

[1]. Browning, M. L. (2007). Keratoconjunctivitis (Pinkeye) in Goats. [Electronic version]. Extension Animal Scientist, AlabamaA\&M University, UNP-88.

[2]. Drovers CattleNetwork news. (2011). Pinkeye and pinkeye prevention: Fly Control Resource Center retrieved October 24, 2013 from http://www.cattlenetwork.com/cattle-resources/fly-control/Pinkeye-and-pinkeye-prevention-122872929.html

[3]. Faez Firdaus Jesse Abdullah, Lawan Adamu, Abdinasir Yusuf Osman, Abdul Wahid Haron and Abdul Aziz Saharee (2013). Clinical Management of stage III infectious bovine Keratoconjunctivitis associated with Staphylococcus aureus in a dairy cow: A case report. Journal of Agriculture and Veterinary Science IOSR, 4(4): 69-73.

[4]. Gasparotto, S. W. (2009). Pinkeye in Goats. Retrieved October 29, 2013, from http://www.tennesseemeatgoats.com/articles2/pinkeyeingoats.html

[5]. Giacometti, M., Janovsky, M., Belloy, L. and Frey, J. (2002).Infectious keratoconjunctivitis of ibex, chamois and other Caprinae. Revue Scientific et Technique (International Office of Epidzootics), 21(2):335-345.

[6]. Kodjo, A., Tonjum, T., Richard, Y., and Bovre., K. (1995). Moraxella caprae sp. nov., a New Member of the Classical Moraxellae with Very Close Affinity to Moraxella bovis.Journal of Systemic Bacteriology, 45(3), 467-471.

[7]. Matthews, J. G. (2009). Diseases of the Goat. United Kingdom: Blackwell Publishing Ltd.

[8]. Pugh D.G. and Baird A.N. (2012).Sheep and goat medicine. Missouri: Elsevier Saunders Inc

[9]. Rathert, C.C. (2008). Goat Diseases and Farm Herd- Health Safety: University of South Carolina, Arnold School of Public Health.

[10]. Whittier, W.D., Currin, N., and Currin, J. (2009).Pinkeye in Beef Cattle.Virginia Cooperative Extension, College of Agriculture and Life Sciences, Virginia Polytechnic Institute and State University, publication 400-750. 